\title{
Estética do performativo ou o fim do teatro de pesquisa dos grandes mestres pedagogos? Eugenio Barba, Presente!*
}

Martha Ribeiro*

RESUMO: Neste estudo coloca-se em questão se o teatro de pesquisa dos grandes mestres pedagogos do século XX, no qual Barba é herdeiro, seria o último baluarte de um teatro que se investe, de forma artesanal, contra a doxa institucionalizada pelas práticas pós-dramáticas ou da estética do performativo, que em sua consagração mundial vem sistematicamente sacrificando e esvaziando de significado ou importância aquilo que na essência se constitui a base de pesquisa dos mestres pedagogos, de toda uma geração: a busca pela arte secreta do ator.

PALAVRAS-CHAVE: Eugenio Barba; Estética do performativo; Dramaturgia do ator.

\footnotetext{
*Eugenio Barba é mestre pedagogo e diretor teatral, a frente do Odin Teatret desde sua fundação em 1964 e criador da ISTA em 1979 (International School of Theatre Antropology). Dentre suas obras publicadas e traduzidas no Brasil destacam-se: "A arte secreta do ator: dicionário de antropologia teatral," organizado em parceria com o historiador teatral Nicola Savaresi, "Canoa de papel: tratado de antropologia teatral," "Terra de cinzas e diamantes: minha aprendizagem na Polônia", "Queimar a Casa: origens de um diretor", entre outros escritos, não menos importantes.

* Martha Ribeiro é diretora e pesquisadora teatral, professora de teoria e história do teatro no Departamento de Arte e no Mestrado em Estudos contemporâneos das Artes da Universidade Federal Fluminense. Coordena o Laboratório de Criação e Investigação da Cena Contemporânea, desenvolvendo as seguintes pesquisas: "Pirandello Contemporâneo" e "Paisagem e Retrato como dispositivos de cena". Realizou com bolsa CAPES (2015-2016) estágio de pós-doutorado na Universidade de Bologna, Dipartimento di Musica e Spettacolo, com a pesquisa "Realismo Sedutor na Cena contemporânea".
} 
ABSTRACT:This study questions the research process of the 20th century's Great Pedagogues and Theatre Masters (considering Eugenio Barba, among his predecessors). Would it be the last bastion of a craftwork theatre against the doxa institutionalized by post dramatical practices or performative aesthetics that have been world consecrated and have been systematically sacrificing itself and emptying the meaning or importance of what in essence is the research base of educators, of a generation: the search for the secret art of the performer.

KEYWORDS: Eugenio Barba; Performative aesthetic; dramaturgy of the actor.

\footnotetext{
Os exercícios corporais são o fundamento para uma espécie de desafio para superar nós mesmos.[...]. Nos exercícios corporais vocês devem manter os elementos concretos, assim como a precisão nos exercícios plásticos. Sem concretude, começa o engano, o rolar pelo chão, os movimentos caóticos, as convulsões [...] (GROTOWSKI, 2010: 176)
}

Escrever sobre Eugenio Barba é se colocar diante de uma história dedicada ao teatro de mais de cinquenta anos. E se projetarmos nosso horizonte para a tradição da qual Barba é herdeiro (junto aos atuantes Peter Brook e Anatoli Vassiliev), dos primeiros mestres pedagogos da arte teatral - de Stanislavski à Grotowski; citando os mais reconhecidos mundialmente -, lá se vão mais de oitenta anos dessa aventura que é fazer, ensinar e pesquisar o teatro e a arte do ator. Barba é um dos poucos homens de teatro que na curva da história é a ponte viva entre os grandes reformadores da cena teatral do inicio do século XX - Stanislavski, Meyerhold, Craig, Piscator, Copeau e Artaud - e os revolucionários artesãos dos anos sessenta - Julian Beck, Judith Malina, Grotowski, Peter Brook e o próprio Barba -, que protagonizaram uma profunda mudança sobre o pensamento da arte teatral: um percurso que ultrapassa uma busca preferencialmente estética para uma busca fundamentalmente ética no teatro, centrada principalmente no trabalho de preparação ou training do ator. Não será nosso trabalho aqui percorrer a linha histórica das etapas que compreendem o panorama teatral entre as duas grandes 
reformas, citando seus protagonistas e suas experiências bem ou mal sucedidas, vissicitudes ou descobertas. Todo esse percurso histórico pode ser consultado facilmente em diversos trabalhos de estudiosos do teatro que exemplarmente vem se dedicando a reconstituir as experiências teatrais da segunda metade do século $X X$, de forma a tornar mais compreensivo o percurso, nem sempre de fácil assimilação, de uma época extremamente fecunda em questionamentos radicais sobre a função da arte teatral, com seu concomitante alargamento imagético'. O que colocamos em questão neste estudo é se o teatro de pesquisa dos grandes mestres pedagogos do século XX, no qual Barba é herdeiro, seria o último baluarte de um teatro que se investe, de forma artesanal, contra a doxa institucionalizada pelas práticas pós-dramáticas ou da estética do performativo, que em sua consagração mundial vem sistematicamente sacrificando e esvaziando de significado ou importância aquilo que na essência se constitui a base de pesquisa dos mestres pedagogos, de toda uma geração: a busca pela arte secreta do ator.

Como bem observa Kuniich Uno o começo é sempre algo complicado: "quando você começa, se não há nada antes de você, você não pode sequer começar, mas se já existe alguma coisa antes de você começar, você não pode verdadeiramente começar" (2012: 65). A complicação é que em relação ao começo é sempre um outro que começa, sendo impossível para qualquer um dominar ou controlar o começo. O interessante na observação de Uno, e que nos interessa destacar, é a relação que o estudioso faz entre a problemática do "começo que não se pode começar", com os interesses de Artaud quando diz: "eu sou um genital inato". O que Artaud vai indicar com essa afirmativa é a vontade de recriar um corpo que tenha o poder de começar. Mas, não se trata apenas de uma vontade de dominar o começo, trata-se de refazer um corpo, sem órgãos, que consiga se libertar de um projeto de dominação da consciência, ou de outro, sobre o corpo: "É o corpo que começa sem querer dominar, como 'genital inato'" (Id.). A grande obsessão de Artaud, analisa Uno, parte da ideia de um "roubo", de uma dominação de Deus sobre seu corpo, que o torna um corpo paralisado, corpo-autômato de Deus. A ideia era refazer, a partir da linguagem teatral, um outro corpo que fosse capaz de acusar, com sua resplandecente vida, toda a ilusão do corpo-fantoche de Deus. Um corpo-vida que se nega a toda ordem, a toda organização, a toda falsificação que paralisa a verdadeira vida, que impede o começo da vida do corpo: "[...] viver é voltar a si mesmo, a todo segundo, com obstinação, e é o esforço que o homem atual não quer mais fazer" (ARTAUD apud UNO, 
Ibdem: 67). A necessidade de que fala Artaud em "voltar a si mesmo" como única possibilidade de refazer o corpo, de dar vida a um novo corpo, se coaduna aos interesses de Barba descritos na arte secreta do ator, e mais especificamente ao profundo significado do training para a dramaturgia do ator. Se é certo, como diz o próprio Barba, que a maior revolução do teatro do século XX foi a revolução do invisível, torna-se importante compreender como as diferentes experiências teatrais do período pensaram esse invisível. Verificam-se de um lado experiências teatrais que buscam revelar em formas visíveis o invisível, como, por exemplo, as experiências cênicas de um teatro naturalista ou realista brechtiano, e de outro lado experiências teatrais que provocam a percepção visionária do invisível. Para Barba, como para os mestres pedagogos de forma geral, o invisível não é algo a se descobrir para compreender melhor a realidade, mas "alguma coisa a se recriar na cena de forma a dar ao artificio teatral um eficaz poder de vida" (BARBA, 1997: 11)2. O invisível que alude Barba é aquilo que transcende a própria materialidade do espetacular, e este invisível é a sub-partitura do ator: campo da pré-expressividade, corpo memória, corpo-mente do ator.

A base da experiência e construção teórica de Barba, desde seus primórdios, nasce a partir dos seus estudos sobre a arte e técnica do ator, mas especialmente por uma relação humana mais ética do que estética, baseando suas escolhas pela personalidade, caráter e força de ânimo dos que, rejeitados ou marginalizados pelo mundo teatral "oficial", procuravam o Odin. Essa é talvez a maior diferença, e a mais significativa, entre a perspectiva do performativo e a perspectiva do teatro de pesquisa, ou do "Terzo Teatro", como nomeia Barba, nos anos 70, o teatro que nasce à margem ou fora dos centros e das capitais da cultura, e que elabora sua própria e autônoma cultura cênica ${ }^{3}$. Distancia que se amplia ainda mais se levarmos em consideração as dificuldades enfrentadas pelos grupos de pesquisa dos mestres pedagogos em começar, enfrentando circunstâncias muito desfavoráveis e hostis. Uma realidade oposta ao clima favorável, de euforia, aceitação e absorção das propostas dos happenings, lançada pelos artistas visuais dos anos sessenta. Não negamos com isso a irrefutável importância da reviravolta performativa para o alargamento conceitual do significado de teatralidade. Quando Allan Kaprow apresentou em 1959 o espetáculo "18 happenings in 6 parts" na galeria Reuben em Nova York, definindo o experimento como happening, uma forma radicalmente nova de fazer e conceber o teatro, consagrou-se junto ao fenômeno uma rejeição às principais bases do teatro moderno, quais sejam: o texto teatral fabulesco; a relação ficcional ator e personagem; 


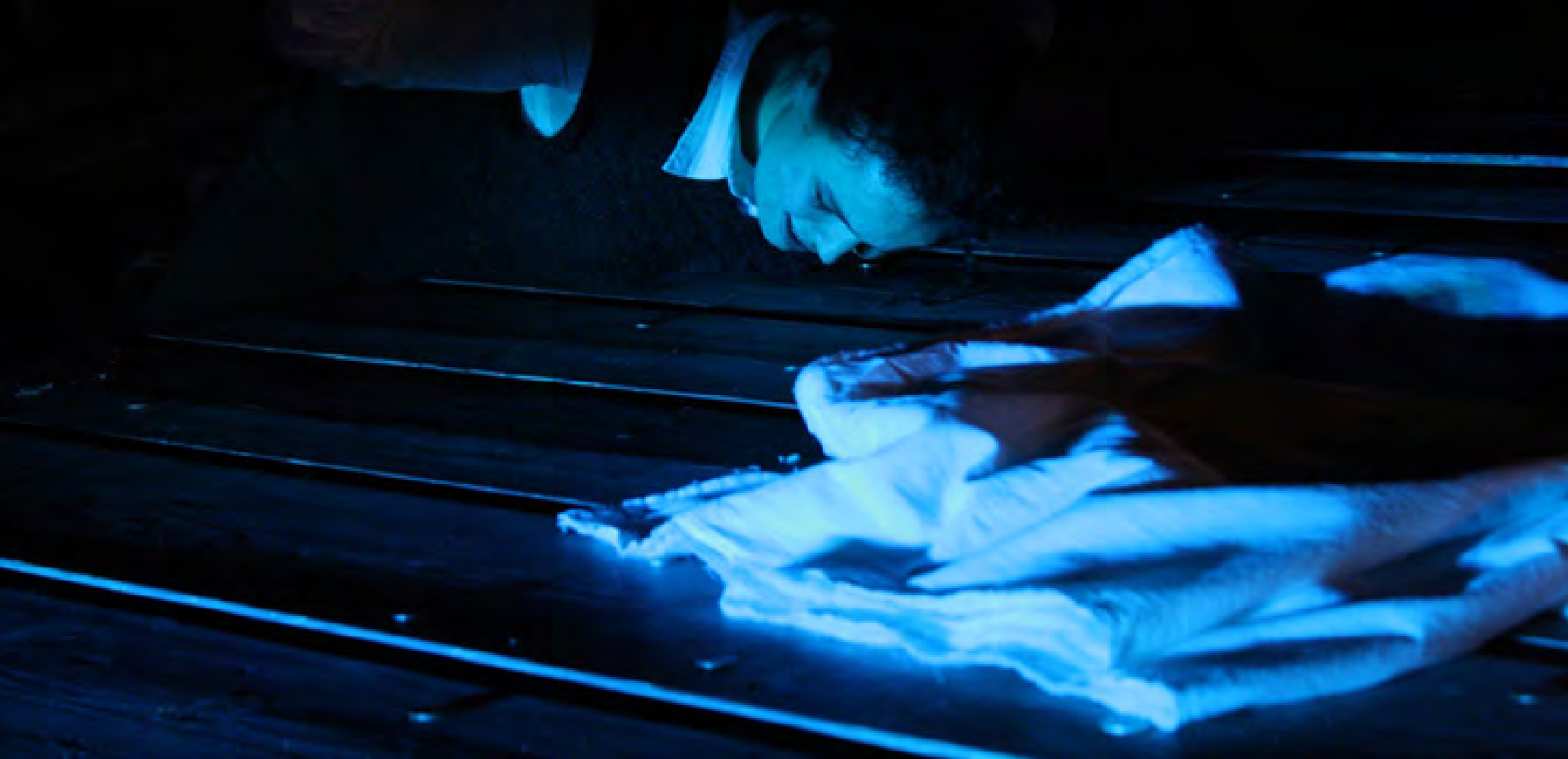

The Chronic Life

Fotografia: Rina Skeel

Fonte: http://odinteatret.dk/ 
o primado da encenação; a matriz espaço-tempo; e a concepção de público enquanto voyeur. A própria noção de teatro irá sofrer um alargamento tal que ameaça mesmo a própria existência do teatro (ou pelo menos do que se entendia por teatro). O happening que não nasce do teatro, mas das artes visuais, reclama para si a categoria de teatro - um teatro visual, mas ainda assim teatro, defende Michael Kirby, primeiro teórico do fenômeno. Mas de um teatro que por sua ótica elimina toda possibilidade de criação de um mundo imaginário e ilusório. As ações realizadas no happening são concretas, não possuem matriz de tempo ou de espaço, ou seja, não criam um mundo imaginário, no qual o espectador mantém uma relação dialética entre identificação e distanciamento. Seus "atores" são mais executores do que propriamente atores, pois equivalem à objetos, Ihes sendo vetada a criação improvisada. Uma perspectiva sobre o ator completamente diferente da seguida por Barba e pelos principais mestres pedagogos do novo teatro. Do advento do happening nos Estados Unidos até o apogeu da performance contemporânea, uma série de mudanças ocorreram no panorama teatral e no pensamento sobre a performance. Mas é irrefutável que a estética do performativo ou do pós-dramático, para utilizarmos um termo cunhado pelo teórico alemão Hans-Thies Lehmann, se institucionalizou tão profundamente na Alemanha (como se observa também hoje no Brasil), ao ponto do encenador Thomas Ostermeier, por suas encenações "realistas" e críticas agudas ao performativo, vir a ser considerado pelo critico francês Georges Banu, como um guerreiro na contracorrente da cena Alemã. Sobre a onipresença do performativo e a evidência do performer nas universidades alemãs, testemunha Ostermeier: "[...] todo discurso dramático e realista é terrivelmente suspeito, porque é "simplesmente" teatro: tem diálogo, personagem, conflito, uma situação cênica. E isso não interessa aos universitários" (2016:36).

O teatro de pesquisa de Barba coloca em primeiro plano a arte artesanal do ator: o processo criativo, à imaginação, a espontaneidade, mas também seu rigor físico e mental, seu treinamento constante e organicidade no trabalho executado. Todo esse caminho investigativo, baseado no trabalho do ator, parte das ações físicas e de técnicas que Barba denomina como extra-cotidianas. O interessante à sublinhar é que o trabalho de Barba sobre o ator se pauta no indivíduo, o training não vale para todos indiscriminadamente, ele se direciona de forma exclusiva e diferenciada para cada um de seus atores, mas esse direcionamento individual dos exercícios é o caminho que Barba se utiliza para aprofundar e ao mesmo tempo ultrapassar os aspectos individuais e as particularidades estilísticas e culturais dos diferentes atores e 
alcançar o nível da pré-expressividade (campo de pesquisa da Antropologia Teatral que estuda o comportamento pré-expressivo do ser humano em situação de representação organizada). A personalidade do ator, sua sensibilidade e inteligência artística, o contexto cultural e tradição cênica nas quais este se insere são aspectos coligados à representação. Já o nível da pré-expressividade, na afirmação do pedagogo, é "o que não varia sob as individualidades pessoais, estilísticas e culturais. É o nível do bios cênico, o nível 'biológico' do teatro sobre o qual se fundam as diversas técnicas" (BARBA, 2009: 27). Esses três níveis de organização, nos quais se fundamenta o trabalho do ator, compõem a sub-partitura: àquilo que é invisível ao espectador, mas que dá vida ao que o espectador vê, ou seja, à partitura, ou melhor, à dramaturgia do ator. No texto "Un amuleto fatto di memoria. II significato degli esercizi nella drammaturgia dell'attore" ${ }^{4}$, Barba vai tecer considerações sobre a sub-partitura e o que ele denomina como "a revolução do invisível" no teatro do século XX, responsável por criar a "era dos exercícios". Sobre o que vem a ser a subpartitura ele assim explica: a subpartitura é um processo profundamente íntimo do ator, que não é facilmente entendido por meio de palavras, que pode ser uma ressonância, um motor, "um nível de organização celular sobre o qual se regulam os outros níveis de organização (da eficácia da presença individual dos atores, ao entrelaçamento de suas relações; da organização do espaço, às escolhas dramaturgicas)" (BARBA, 1997:11). O treinamento pré-expressivo é fundamental para a dramaturgia do ator, com estímulos a níveis mais profundos, para uma criação orgânica e transcultural. Pela importância dos exercícios para a pedagogia do ator - é da partitura de um exercício que se desenvolve a sub-partitura, dirá Barba -, acreditamos ser fundamental transcrever em sua totalidade as 10 características elencadas pelo mestre pedagogo:

Os exercícios são pequenos labirintos que o corpo-mente do ator pode percorrer e percorrer novamente para incorporar um modo de pensar paradoxal, para distanciar-se do próprio agir cotidiano e entrar no campo do agir extra-cotidiano do palco. [...] Um exercício é feito de memória: memória do corpo. Um exercício se torna memória e age através do corpo inteiro. [...] 1- Os exercícios são em primeiro lugar uma ficção pedagógica. O ator aprende a não aprender a ser um ator, ou seja a não aprender a interpretar. $O$ exercício ensina a pensar preferencialmente com o corpo-mente. 2- Os exercícios ensinam a executar uma ação real (não "realista", mas rean. 3- Os exercícios ensinam que a precisão da forma é essencial em uma ação real. O exercício tem um início e um fim, e o percurso entre estes dois pontos não é linear, mas 
rico de peripécias, de mudanças, de saltos e curvas e contrastes. 4- A forma dinâmica de uma exercício é um continuum constituído por uma série de fases. Para apreende-lo com precisão precisa ser segmentado. Este processo ensina o continuum como uma sucessão de fases minúsculas bem definidas (ações perceptíveis). O exercício é como um ideograma e - como todo ideograma - é constituído por traços que devem ser executados sempre segundo a mesma sucessão. Pode-se variar a espessura, a intensidade e o ímpeto do traço individual. 5- Cada fase do exercício envolve o corpo inteiro. A transição de uma fase a outra é um sats. 6- Cada fase do exercício dilata, refina ou abrevia alguns dinamismos do comportamento cotidiano. Estes dinamismos vem assim isolados e montados, sublinhando o jogo das tensões, dos contrastes e das oposições, isto é, dos elementos de uma dramaticidade elementar que transforma o comportamento cotidiano no extra-cotidiano da cena. 7- As diversas fases do exercícios permitem experimentar o próprio corpo como alguma coisa que não é unitária, e que em troca transforma-se numa sede de ações simultâneas. Esta experiência coincide, num primeiro momento, com um doloroso sentimento de desapropriação da própria espontaneidade. Mas, logo em seguida se transforma na pedra basilar do ator, na sua presença pronta para projetar-se em diferentes direções, capaz de atrair a atenção do espectador. 8- O exercício ensina a repetir. Aprender a repetir não é difícil, o problema é saber executar uma partitura cada vez com maior precisão. Torna-se difícil no seguinte estágio: continuar a repetir sem perder o entusiasmo, descobrindo novos detalhes, motivando novos pontos de partida dentro da mesma partitura. 9- O exercício é a via do desapego: ensina a renuncia através do compromisso com uma tarefa cansativa e humilde. 10- O exercício não é um trabalho sobre o texto, mas sobre si mesmo. Coloca o ator à prova através de uma série de obstáculos. Permite ao indivíduo conhecer-se através do encontro com os próprios limites, e não pela auto-análise (Ibdem: 15,16) ${ }^{5}$.

O exercício seria uma espécie de trampolim para o ator alcançar o invisível, isto é, a subpartitura, os princípios pré-expressivos que sustentam a técnica do ator. Não seria viável partir do próprio invisível, por isso a importância do training - técnicas extra-cotidianas - para a dramaturgia do ator. Os exercícios trabalham escavando as camadas do visível, formas vazias passíveis de repetição. A repetição, de cada fase sucessiva, cria uma partitura visível, e somente a partir dela poderá o ator desenvolver uma subpartitura, um espaço anterior, íntimo, memorial: "O diálogo entre o visível e o invisível é exatamente aquilo que o ator percebe como interioridade e em alguns casos até mesmo como meditação. E é aquilo que o espectador experimenta como interpretação" (ld.). A preocupação pedagógica com o trabalho do ator, 
Inside the Skeleton of the Whale

Fotografia: Tony D'Urso

Fonte: http://odinteatret.dk/ 
que se desenvolve em um solido trabalho de pesquisa sobre o visível e o invisível, partitura e sub-partitura, reflete a enorme distancia entre o teatro de pesquisa de Barba, um teatro que antes de ser dramático é um teatro-laboratório, e o teatro visual, "interdisciplinar", do happening, responsável pela reviravolta performativa no teatro, e o posterior desenvolvimento de uma estética do performativo. Os primeiros comentadores do happening, como Michael Kirby e Susan Sontag, constataram na forma artística do fenômeno uma anestesia emocional dos executores, que abandonam a matriz espaço-tempo-personagem para se comportarem como objetos. Enquanto o teatro dos mestres pedagogos como Barba, Grotowski, Brook e Vassiliev se fundamentam exclusivamente no trabalho do ator, na busca de um teatro sagrado, ritual, apartado da realidade cotidiana, o happening ou a estética visual do performativo, com o objetivo de sacudir o publico de sua tradicional passividade, preocupado em provocar choques emocionais no espectador, preenche o espaço cênico com imagens de pessoas-objetos, anestesiadas, que a partir de uma ação ao mesmo tempo marcada pelo "seu caráter cerimonial e pela inutilidade", se caracteriza "por situações de dissociação mecânicas e sem sentido" (SONTAG, 1987: 316,317). Duas linhas de pesquisa antagônicas no modo de ver e de pensar a arte, sintetiza Marinis (2000: 197) : se de um lado (happening, Cage, Duchamp, Pop-art) temos uma concepção de arte como um espaço contíguo ou imerso na vida cotidiana, tecnológica e de consumo; de outro (Grotowski, Brook, Barba, Artaud, Fuchs) todo um campo de pesquisa do teatro enquanto um espaço-tempo sagrado em antítese com a vida cotidiana, dedicado a fazer do teatro um espaço mágico-ritual.

Pensar em dramaturgia do ator é pensar no trabalho do ator sobre si, é pensar em teatro-laboratório, é pensar em Stanislavsky, Meierhold, Copeau, Brook, Mnouchkine, é pensar no Teatro das "13 filas" de Grotowski, fundado em 1959, é pensar no ISTA, Internacional School of Theatre Anthropology, fundado por Barba em 1979. No entanto a noção de teatro-laboratório começa a ser tema de discussão entre a segunda metade dos anos noventa e o inicio do novo século a partir de um simpósio internacional organizado em homenagem ao aniversario de 40 anos do Odin Teatret: "Why a Theatre Laboratory? Riskys and Innovation in Europe 1898-1999". Para o simpósio, Barba propôs aos participantes desenvolver o tema a partir de 12 afirmações por ele desenvolvidas, podendo cada estudioso escolher aquela que mais the interessasse, seja por semelhança ou por dissonância ao modo de pensar de cada um. Não teremos espaço para transcrever as 12 proposições, então seguiremos a sugestão de Barba, 
colocando em evidencia uma ou duas. Citamos as proposições seis e nove: "6. No teatro-laboratório a pesquisa é conduzida não em vista da criação de eventos, mas pela criação de um ambiente no qual seja possível desenvolver um trabalho continuado"; e, completando à proposição seis: "9. Entre os fundamentos da profissão cênica, privilegia aqueles que se referem ao ator" (BARBA apud MARINIS, 2013:174). É fácil identificar a importância das proposições seis e nove para o desenvolvimento de uma metodologia para o ator. A criação de um ambiente de trabalho, a sistemática de exercícios rítmicos, de respiração, de composição e concentração, permite que o ator enriqueça seus meios de expressão e, principalmente, aprenda a controlar seu corpo evitando o caos generalizado, "as convulsões sem sentido". Em outras palavras, o ator aprende a fazer de seu corpo um expressivo instrumento artístico. Para a teórica Erika Fisher-Lichte, a expressividade seria o exato contrário da performatividade, que desestabiliza o esquema conceitual dicotômico, como por exemplo ator e personagem: "os atos performativos devem ser considerados como não referenciais, porque não se reportam a alguma coisa já dada, interiorizada, a uma substancia ou a uma essência que estes deveriam exprimir" (FISHER-LICHTE, 2014: 47). Não existiria assim, para o conceito de performativo, uma identidade fixa, uma essência que as ações do corpo pudessem exprimir. É o próprio ato performativo que constrói uma identidade. Ou seja, o performativo é aquilo que produz o que é executado, e expressividade é a expressão de algo que está em outro lugar. Por essa afirmativa, os três princípios apontados por Barba, especialmente o nível de pré-expressividade, considerado por ele invariável, seriam a antítese do conceito de performativo.

É unanime entre os estudiosos, e matéria irrefutável, que interpretar um papel não passa por nenhum processo de identificação. Para Barba, o personagem seria um instrumento que o ator se utiliza para penetrar em sua própria intimidade, para se desnudar: "É um processo de auto-penetração, de excesso, sem o qual não pode existir criação profunda, contato com os outros, possibilidade de formular interrogações angustiantes que voluntariamente evitamos para preservar o nosso limbo cotidiano" (2010: 99). Esse ato de desnudamento, através do personagem, que seria um veículo para o auto-conhecimento, é o que garante uma expressividade mais profunda, dirá Barba, totalmente diferente de uma expressividade alcançada pela via de uma identificação com o personagem. O teatro laboratório, através dos exercícios, busca eliminar as resistências dos atores, os clichês de cena, alcançar o "reservatório de experiências hereditárias" e transformar esse campo pré-expressivo em partitura, isto é, 
em expressão artística. Voltando a Fisher-Lichte, a teórica deixa claro que o conceito de performativo perpassa pela fisicalidade, pela corporeidade, e que por essa perspectiva, não se apreende uma emoção como algo que existe interiormente e que tenho que expressar. No performativo são os gestos e as expressões faciais que articulam a emoção; se o gesto não ocorre, a emoção não existe. Já para Barba, a emoção encontra-se em um espaço interior, nesse "reservatório de experiências", e que para ser alcançada o ator precisa se auto-investir, através de incontáveis repetições da partitura, de cada detalhe, até conseguir uma unidade entre o seu corpo e o pensamento. O training possui um papel fundamental para o processo criador, para a dialética entre disciplina e espontaneidade, entre forma e reação orgânica. Sem a estrutura, afirma Barba, todo gesto e toda ação física tende a se degenerar de forma caótica, se perdendo numa inexpressiva convulsão e descontrole. As declarações de Julia Varley, atriz do Odin desde 1976, nos convence sobre a importância do training para se evitar tanto o corpo-autômato, desejado nos happenings e presente em diversas performances contemporâneas, ou seu oposto, o corpo-convulso das performances consideradas "emocionais" ou "viscerais":

Quando o pensamento voa junto à ação, concentrado e livre para aventurar-se, [...] sei que consegui construir uma situação na qual combato o perigo de me transformar em um robô que conhece apenas o percurso estabelecido. [...] O corpo é inteligente, preparado e não automático, depois que se libertou da dificuldade de lembrar [da partitura]. Assim, no espetáculo, podemos fazer emergir aqueles átomos de iluminação emocional, quando de repente dois elementos se encontram e acreditam ter agarrado algo. Para eu chegar neste estado é necessário que a partitura esteja completamente apreendida, ao ponto de poder esquece-la. (1997:115)6

Sobre o significado de "expressar uma emoção", Barba vai explicar que a arte dos atores está em reconstruir, através da sub-partitura e partitura (o invisível-tornado-visível), não o sentimento, mas a complexidade das emoções, que, embora pertença ao invisível, é fisicamente concreta. Os exercícios ensinam esse caminho: desenvolver as diferentes fases da emoção, sem cair na tentação de expressar o sentimento. Ou seja, o medo possui uma estrutura de nervos, ritmos, sons e gestos que podem ser artificialmente reconstruídos pelos exercícios. Essa complexidade visível, trabalhada em fases, compõe a dramaturgia do ator, que investiga uma emoção enquanto um complexo de reações a um estimulo. Em nossa hipótese, a arte secreta do ator, proposta por Barba, é a "via negativa" da estética do performativo. No sentido 
em que elimina a interdisciplinaridade própria a esses espetáculos híbridos, de integração de técnicas sofisticadas, como video e telas cinematográficas, concentrando-se no que o performativo deixou de investigar: a arte "pobre" do ator. Uma vez Ariane Mnouchkine lamentou que a profissão de ator seria uma arte fadada ao esquecimento. Lhe faltaria espaço em nossa época globalizada e midiatizada? Onde o jovem estudante das artes questiona as dificuldades da profissão e seu longo tempo de preparação, perguntando-se: " por que ser ator se eu posso ser performer?". E aqui vale lembrar que todo ator é um performer, mas nem todo performer é um ator. Esperamos que Mnouchkine esteja errada, pois como disse Brook, já faz alguns anos, em relação ao teatro pobre de Grotowski: é na pobreza de um teatro que sacrifica tudo, menos o ator, que encontramos o teatro mais rico do mundo.

\section{Notas}

1 Indicamos os trabalhos dos seguintes estudiosos italianos: Marco De Marinis, Lorenzo Mango, Valentina Valentini, Antonio Attisani, que ao longo do tempo vem se dedicando a pesquisar e organizar as experiências teatrais da segunda metade do século XX. 2 Tradução minha.

3 “Procurando relações mais humanas entre os homens, com a intenção de realizar uma célula social, na qual as intenções, aspirações, as necessidades pessoais comecem a se transformarem em fatos. [...] Este é o paradoxo do Terzo Teatro: emergir, como grupo, no cerco do fingimento para encontrar a coragem de não fingir" (BARBA: 2000:165)

4 Considerações apresentadas durante a "IX Sessione dell'Ista" em Umea, Suécia , maio de 1995. Publicado em "Drammaturgia dell'attore, Teatro Eurasiano, n.3, 1997, organização Marco De Marinis.

5 Tradução minha.

6 Tradução minha.

\section{Referências}

BARBA, Eugenio. Un amuleto fatto di memoria. II significato degli esercizi nella drammaturgia dell'attore. In_Drammaturgia dell'attore. DE MARINIS, Marco (Org). Teatro Eurasiano, n.3, 1997. Teatro. Solitudine, mestiere, rivolta. Milano: Ubulibri, 2000.

. A canoa de papel. Tratado de Antropologia Teatral. Brasilia: Dulcina Editora, 2009.

BROOK, Peter. O teatro e seu espaço. Petrópolis: Editora Vozes, 1970.

DE MARINIS, Marco. I/ teatro dopo I'età d'oro. Roma: Bulzoni Editore, 2013.

El nuevo teatro, 1947-1970. Barcelona: Paidós, 1988.

Capire il teatro. Lineamenti di una nuova teatrologia. Roma: Bulzoni, 2000. 
FISCHER-LICHTE, Erika. Estetica del performativo, una teoria del teatro e dell'arte. Roma: Carocci editore, 2014.

GROTOWSKI, Jersy. POLASTRELLI, Carla (Org.). O Teatro Laboratório de Jerzy Grotowski 1959-1969. São Paulo: Fondazione Pontedera Teatro/Edições SESCSP/ Perspectiva, 2010.

0
0
0
0
0
0
0
0
$E$
0
0
0
0
0
0
0
0
0
0
0
0
0
0
0
0
0
0
0
0
0
0
0
0
0
0
0

OSTERMEIER, Thomas. BANU, Georges (Org.) Le Théâtre et la peur. France: Actes Sud, 2016.

SONTAG, Susan. Contra a interpretação. Porto Alegre: LPM, 1987.

UNO, Kuniich. A Gênese de um corpo desconhecido. São Paulo: n-1 edições, 2012.

VARLEY, Julia. Sottopartitura: ancora un termine utile e sbagliato. Risposte a Patrice Pavis. In_Drammaturgia dell'attore. DE MARINIS, Marco (Org). Teatro Eurasiano, n.3, 1997. 